\title{
The functional impairment of different subtypes and occupational states in euthymic patients with bipolar disorder
}

\author{
Xinyu Liu ${ }^{1,2}$, Xiaojuan $\mathrm{Ma}^{3}$, Wenchen Wang ${ }^{2}$, Jian Zhang ${ }^{2}$, Xia Sun ${ }^{2}$, Xingguang Luo ${ }^{4}$ and Yong Zhang ${ }^{1,2^{*}}$
}

\begin{abstract}
Background: The aim was to explore the associations between clinical symptoms, demographic variables, social and neurocognitive functioning in euthymic patients with bipolar disorder (BD) stratified by subgroups of DSM-IV BD (type I (BD-I) and type II (BD-III)) and occupational status (employed/unemployed), and to highlight the significance of occupational status when assessing social and neurocognitive functioning in euthymic BD patients.

Methods: A total of 81 euthymic BD patients were participated in the study. The severity of the depressive and manic/hypomanic symptoms was measured using the 17-item Hamilton Depression Rating Scale (HDRS-17) and the Young Mania Rating Scale (YMRS), respectively. Social functioning and neurocognitive functioning were evaluated by the Functioning Assessment Short Test (FAST) and neurocognitive measures, respectively.

Results: Employed BD patients displayed greater social functioning (autonomy, occupational functioning, interpersonal relationship domain) and better verbal learning performance and speed of processing than unemployed BD patients. The correlation between neurocognitive functioning and social functioning was stronger in the employed group than in the unemployed group. There were no significant differences in neurocognitive and social functioning between the BD-I and BD-II groups, and the correlation between neurocognitive functioning and social functioning was similar between the BD-I and BD-II groups.
\end{abstract}

Conclusion: Employed BD patients may present greater occupational functioning and interpersonal relationships, as well as better verbal learning performance and speed of processing.

Keywords: Bipolar disorder, Social functioning, Neurocognitive functioning, Employed, Unemployed, Subtype

\section{Background}

As a recurrent and chronic illness, bipolar disorder (BD) is a complex mental disorder characterized by pathological mood instability [1], that affects $2.4 \%$ of the global population [2]. The lifetime prevalence of bipolar disorder was $0.6 \%$ according to the China Mental Health Survey in 2012 [3]. Bipolar disorder is reported to be

\footnotetext{
* Correspondence: zhangyong@tjmhc.com

${ }^{1}$ Henan Key Laboratory of Neurorestoratology, the first Affiliated Hospital of Xinxiang Medical University, Xinxiang, China

Unit of Bipolar Disorder, Tianjin Anding Hospital, 13 Liulin Road, Hexi District, Tianjin 300222, China

Full list of author information is available at the end of the article
}

one of the top 20 causes of the global disease burden [4], with documented moderate to severe social and neurocognitive functional impairment [5].

Despite optimal treatment with mood stabilizers and second-generation antipsychotics, social and neurocognitive dysfunction in $\mathrm{BD}$ remains a serious problem. It is reported that $60-70 \%$ of $\mathrm{BD}$ patients have varying degrees of impairment in social and occupational functions [6]. Some findings have indicated that social and neurocognitive functional impairment persists among patients with bipolar disorder, not only at the acute stage of the illness but also in remission [7, 8]. Another research has

C C The Author(s). 2021 Open Access This article is licensed under a Creative Commons Attribution 4.0 International License, which permits use, sharing, adaptation, distribution and reproduction in any medium or format, as long as you give appropriate credit to the original author(s) and the source, provide a link to the Creative Commons licence, and indicate if changes were made. The images or other third party material in this article are included in the article's Creative Commons licence, unless indicated otherwise in a credit line to the material. If material is not included in the article's Creative Commons licence and your intended use is not permitted by statutory regulation or exceeds the permitted use, you will need to obtain permission directly from the copyright holder. To view a copy of this licence, visit http://creativecommons.org/licenses/by/4.0/ The Creative Commons Public Domain Dedication waiver (http://creativecommons.org/publicdomain/zero/1.0/) applies to the data made available in this article, unless otherwise stated in a credit line to the data. 
shown that only $37.6 \%$ of the 219 BD patients achieved recovery in social functioning assessed by Global Assessment Functioning (GAF) scores after 2 years of hospitalization [9]. Social dysfunction manifests itself in a subgroup of patients even at the onset of the disease [9].

Although there are apparent social function deficits in BD patients [10], research on the differences in social function impairments between the bipolar disorder type I (BD-I) and type II (BD-II) is still inconsistent. Ruggero et al. did not find a difference in GAF scores between BD-I and BD-II patients [11]. However, Dell'Osso and his colleagues found that remitted BD and BD-I patients had significantly lower GAF scores than BD-II patients [12]. In contrast, recent studies have found differences in social function between those with BD-I and BD-II in the early stage of BD [13], suggesting that BD-II patients presented more cognitive complaints assessed by the Massachusetts General Hospital Cognitive and Physical Functioning Questionnaire and lower overall functioning when Functioning Assessment Short Test (FAST) was used to evaluate the social function. The reasons for the discrepancy in functional outcomes may be due to different assessment tools, duration of illness, education level, and pre-disease cognitive reserve [13, 14]. In terms of neurocognitive function, the prevailing view was that BD-II patients perform better than BD-I patients, but recent research has tended to support the opinion that there is no difference in neurocognitive function between the BD subtypes [15]. A meta-analysis concluded that neurocognitive differences between BD-I and BD-II are not distinct [16], which is in line with Dittmann et al.'s findings in which the Repeatable Battery for the Assessment of Neuropsychological Status (RBANS) was used to assess cognitive impairment [17].

The correlation between neurocognitive impairment and occupational status in BD patients has been mentioned in earlier studies. Altshuler et al.'s findings showed that poor executive function may lead to decreased occupational opportunities [18]. Further research suggested that working memory and speed of processing were significantly associated with occupational function in BD patients [19]. Recent findings have indicated that social function may play a core role in employment development in BD patients [20]. However, to our knowledge, there are still few studies comprehensively comparing the specific characteristics of impairment of social functioning in euthymic BD patients with different occupational status. Moreover, previous findings have been insufficient. Some functioning instrument such as GAF or the Social and Occupational Functioning Assessment Scale (SOFAS) most failed to cover all aspects of functioning in BD patients [21]. Additionally, the assessments on cognitive impairment have been also diverse, which caused inconsistence on functioning outcomes. Therefore, the efficient and multi-dimensional instruments are more likely to reflect real functional impairment in BD patients. We firstly choose the Functioning Assessment Short Test (FAST) and the MATRICS Consensus Cognitive Battery (MCCB) to evaluate the psychosocial and cognitive impairments, which could reflect real and overall functional impairments in euthymic BD patients. Our earlier findings have evidenced they had better ability of assessment to overall functioning both in BD patient and major depressive disorder patient $[22,23]$.

The purpose of this study was to examine the functional differences between occupational status and between subtypes in order to compare the correlation of neurocognition and social function in BD patients based on different occupational status and BD subtypes. We hypothesize that employed BD patients displayed greater scores based on the FAST assessment and better cognitive performance based on the MCCB, and euthymic BD-I patients may perform better social functioning compared to those of euthymic BD-II patients, Besides, the correlation between neurocognitive functioning and social functioning was stronger in the employed $\mathrm{BD}$ patients than in the unemployed BD patients.

\section{Methods \\ Participants}

Euthymic patients with bipolar disorder aged 18-60 years were recruited consecutively from Tianjin Anding Hospital between June and December 2018. Euthymic BD patients were defined as those with YMRS total score $\leq 6$, HDRS-17 total score $\leq 8$ and in clinical remission for at least one month [22]. Our preliminary study mainly screened BD patients who were currently euthymic, we assessed currently remitted state regardless of the number of past episodes.

Demographic information was obtained during clinical interviews. All patients met the diagnosis criteria for bipolar disorder according to the Diagnostic and Statistical Manual of Mental Disorders-fourth edition (DSM-IV) [24]. We had to exclude those patients who had manifested severe physical diseases or alcohol or substance abuse and other severe psychiatric disorders, such as schizophrenia and mental retardation. In addition, those who had received any psychological treatment, such as cognitive behavioral therapy and psychoeducation within the past six months were not included in this study. Patients who had received MECT treatment within the past six months were excluded. All recruited BD patients were permitted to use typical antipsychotic and mood stabilizer medications. We received approval from the Ethics Committee of Tianjin Anding Hospital. Written informed consent was obtained from all participants. 
Occupational data was obtained as part of the clinical interview. All participants were divided into two groups based on current occupational status: employed and unemployed. Participants in the employed group consisted of individuals who were currently employed full-time (any occupational category) or enrolled as a full-time student. All participants in the unemployed group consisted of those who were currently unemployed. Participants who were retired $(n=1)$ or a "housewife" $(n=2)$ were excluded to clearly define both employed and unemployed groups [25].

\section{Assessments and materials}

We collected sociodemographic characteristics including age, sex, education level, employment, duration of BD, family history and medication treatments in the clinical interview. The severity of the depressive and manic/ hypomanic symptoms was measured using the 17-item Hamilton Depression Rating Scale (HDRS-17) [26] and the Young Mania Rating Scale (YMRS) [27], respectively. Social functional impairment was measured using the Functioning Assessment Short Test (FAST) [28]; the Chinese version of the FAST has been shown to have satisfactory reliability and validity in BD patients [22]. The FAST comprises 24 items assessing six domains of functioning: autonomy, occupational functioning, cognitive functioning, financial issues, interpersonal relationships, and leisure time [28]. The total score is the sum of all items, with a higher score indicating more severe functional impairment. The neurocognitive assessment tool was The MATRICS Consensus Cognitive Battery (MCCB), conducted by an experienced psychiatrist. The Chinese version of MCCB was translated and revised by Yu Xin's team from the Sixth College of Peking University and established the Chinese population norm, which has excellent psychometric characteristics [29]. The speed of processing was estimated with Trail Making Test-A (TMT-A) [30] and the Symbol Digit Modalities Test (SDMT) [31]; verbal learning and visual memory were rated by the Hopkins Verbal Learning Tests-Revised (HVLT-R) and Brief Visuospatial Memory Test-Revised (BVMT-R) [32]. Executive function was evaluated by the Stroop Color-Word Test (SCWT) [33]. Color blindness was assessed in all participants before applying Stroop Color-Word Test.

\section{Statistical analysis}

Data analysis was performed using SPSS Version 25.0 (SPSS, Chicago, IL, USA). Demographic characteristics and clinical variables were compared between the groups using $t$-tests and chi-squared tests. Furthermore, an independent samples $t$-test was conducted to compare the differences in the HDRS-17, YMRS, FAST and neurocognitive measures between groups. The correlations between occupational status, demographic risk factors, clinical symptoms, social functional impairment and neurocognitive measures were assessed by Pearson's partial correlation coefficients. All statistical tests were twotailed, and alpha was set at 0.05 .

\section{Results}

\section{Demographic characteristics for all participants}

Ninety euthymic BD patients were screened in this study, and data for nine patients were excluded due to incomplete assessments. A total of 81 patients (43 male and 38 female) completed all assessments in the interview, including 45 patients with BD-I, 36 patients with BD-II, 45 employed BD patients, and 33 unemployed BD patients. No significant differences were found in demographic characteristics, including age, educational level, marital status, family history, course of $\mathrm{BD}$, and number of episodes, between genders or between BD subtypes. Moreover, we did not find differences in most demographic variables, except for educational levels, between the employed and unemployed groups (see Table 1).

\section{Comparison of the clinical variables between the groups} We compared the clinical measures of HDRS-17, YMRS, and FAST (including its six domains), and the neurocognitive measures between genders, as well as between BD subtype groups. No significant differences in any of the above-mentioned variables were found between genders (all $p$ values $>0.05$ ). There were highly significant group differences in the FAST total scores (including the occupational functioning, cognitive functioning and interpersonal relationship domains) between BD subtype groups. BD-I group had lower scores for these variables than BD-II group, but no differences in neurocognitive measures were found between BD subtype groups (see Table 2). We also compared the clinical measures and

Table 1 Demographic characteristics between employed and unemployed participants.

\begin{tabular}{lllll}
\hline Items & $\begin{array}{l}\text { employed } \\
(\boldsymbol{n}=\mathbf{4 5}) \\
\text { Mean (SD) }\end{array}$ & $\begin{array}{l}\text { unemployed } \\
(\boldsymbol{n}=\mathbf{3 6})\end{array}$ & Xean (SD) & $\boldsymbol{p}$ value \\
\hline $\begin{array}{l}\text { Gender (female) } \\
\text { (n(\%)) }\end{array}$ & $21(46.7 \%)$ & $17(47.2 \%)$ & 0.002 & 0.96 \\
Age (year) & $35.3(7.2)$ & $32.8(10.2)$ & 1.30 & 0.22 \\
Education levels (year) & $14.0(2.8)$ & $11.8(3.3)$ & 3.23 & 0.002 \\
Marital status (n(\%)) & & & & \\
\multicolumn{1}{c}{ single } & $9(20 \%)$ & $18(50 \%)$ & & \\
$\quad$ married & $34(75.6 \%)$ & $10(27.8 \%)$ & & \\
$\quad$ divorced & $2(4.4 \%)$ & $7(19.4 \%)$ & & 0.40 \\
Duration of BD (year) & $7.6(5.5)$ & $8.6(6.1)$ & -0.85 & 0.62 \\
Family history (yes/no) & $8 / 37$ & $8 / 28$ & -0.54 & 0.59 \\
\hline Number of episodes & $3.4(1.8)$ & $3.6(2.2)$ & & \\
\hline
\end{tabular}


Table 2 Comparisons of clinical variables by occupational states and by BD subtypes.

\begin{tabular}{|c|c|c|c|c|c|c|c|c|}
\hline \multirow[t]{2}{*}{ Items } & $\begin{array}{l}\text { employed } \\
(n=45)\end{array}$ & $\begin{array}{l}\text { unemployed } \\
(n=33)\end{array}$ & $t$ & $p$ value & \multirow{2}{*}{$\begin{array}{l}\text { BD-I } \\
(n=45) \\
\text { Mean (SD) }\end{array}$} & $\begin{array}{l}\text { BD-II } \\
(n=36)\end{array}$ & \multirow[t]{2}{*}{$t$} & \multirow[t]{2}{*}{$p$ value } \\
\hline & Mean (SD) & Mean (SD) & & & & Mean (SD) & & \\
\hline HDRS-17 & $3.7(0.9)$ & $3.5(1.1)$ & 0.96 & 0.338 & $3.6(1.0)$ & $3.7(0.9)$ & -0.68 & 0.501 \\
\hline YMRS & $3.0(1.0)$ & $3.5(1.3)$ & -1.88 & 0.064 & $3.8(0.9)$ & $3.6(1.4)$ & 0.27 & 0.131 \\
\hline FAST total & $17.5(2.4)$ & $25.6(2.2)$ & -15.76 & $<0.001$ & $19.5(4.0)$ & $23.1(4.7)$ & -3.81 & $<0.001$ \\
\hline autonomy & $1.5(0.5)$ & $1.9(0.7)$ & -3.07 & 0.003 & $1.6(0.6)$ & $1.8(0.6)$ & -1.47 & 0.145 \\
\hline occupational functioning & $5.2(1.3)$ & $9.0(1.0)$ & -15.13 & $<0.001$ & $6.1(1.8)$ & $7.8(2.3)$ & -3.64 & $<0.001$ \\
\hline cognitive functioning & $2.1(0.5)$ & $2.4(0.5)$ & -2.01 & 0.048 & $2.1(0.5)$ & $2.3(0.5)$ & -2.05 & 0.044 \\
\hline financial issues & $1.6(0.5)$ & $1.7(0.5)$ & -0.87 & 0.385 & $1.7(0.5)$ & $1.6(0.5)$ & 0.51 & 0.610 \\
\hline interpersonal relationships & $5.3(1.2)$ & $9.1(1.2)$ & -13.61 & $<0.001$ & $6.3(2.0)$ & $7.9(2.2)$ & -3.39 & 0.001 \\
\hline leisure time & $1.8(0.5)$ & $1.6(0.5)$ & 1.08 & 0.286 & $1.7(0.5)$ & $1.7(0.5)$ & 0.15 & 0.879 \\
\hline TMT-A & 38.7 (9.9) & $38.6(9.1)$ & 0.04 & 0.971 & 39.4 (9.8) & 37.8 (9.2) & 0.76 & 0.447 \\
\hline SDMT & $49.1(5.7)$ & $40.2(8.9)$ & 5.21 & $<0.001$ & $46.3(8.5)$ & $43.8(8.5)$ & 1.30 & 0.198 \\
\hline HVLT-R & 25.6 (3.6) & 19.7 (2.6) & 8.17 & $<0.001$ & $23.7(4.4)$ & $22.1(4.1)$ & 1.68 & 0.096 \\
\hline BVMT-R & $22.7(4.8)$ & $22.3(4.8)$ & 0.34 & 0.735 & $22.0(4.7)$ & $23.2(4.7)$ & -1.17 & 0.244 \\
\hline SCWT (total) & 179.4 (28.7) & $177.3(31.5)$ & 0.32 & 0.753 & 177.7 (30.3) & $179.4(29.6)$ & -0.26 & 0.797 \\
\hline
\end{tabular}

Note: BD (Bipolar Disorder); TMT-A (Trail Making Test-A); SDMT (Symbol Digit Modalities Test); HVLT-R (Hopkins Verbal Learning Tests-Revised); BVMT-R (Brief Visuospatial Memory Test-Revised); and SCWT (Stroop Color-Word Test)

the functional measures between the employed group and unemployed group. We found no group differences in HDRS-17 or YMRS scores $(p>0.05)$, but there were highly significant group differences in the FAST total scores, as well as in autonomy, occupational functioning, and interpersonal relationship domains, but minor differences in cognitive functioning domain. Employed patients reported lower scores in these domains than unemployed patients. In addition, the employed group reported higher scores on the Symbol Digit Modalities Test $(p<0.001)$ and Hopkins Verbal Learning TestsRevised $(p<0.001)$ than the unemployed group. No other differences in neurocognitive measures were found between the employed group and unemployed group (see Table 2).

\section{Associations between total FAST scores, neurocognitive measures and other clinical variables in stratified sampling}

We examined the correlation between FAST scores and neurocognitive measures and other variables across the BD subtypes. Our results showed that the correlations between FAST scores and neurocognitive measures were similar in the BD-I group and BD-II group. We found that FAST total scores, interpersonal relationships and occupational functioning were negatively associated with higher scores on the Symbol Digit Modalities Test and Hopkins Verbal Learning Tests-Revised in both BD subtypes. In addition, leisure time was moderately correlated with scores on the Brief Visuospatial Memory Test-Revised, and financial issues were moderately correlated with scores on the Hopkins Verbal Learning Tests-Revised in the BD-I group (See Figs. 1, 2).

We also analyzed the correlation between FAST scores and neurocognitive measures and other variables across the employed and unemployed group. As it was statistically significantly different between the employed/unemployed, we used education level as a control variable in the partial correlation analysis. In the employed group, we found that the autonomy domain was negatively related to Stroop Color-Word Test scores and occupational functioning; financial issues was negatively correlated with the Hopkins Verbal Learning TestRevised scores and with interpersonal relationships; and leisure time was correlated with scores on the Symbol Digit Modalities Test and Brief Visuospatial Memory Test-Revised. The FAST total score was negatively associated with higher scores on the Symbol Digit Modalities Test, Hopkins Verbal Learning Test-Revised, Brief Visuospatial Memory Test-Revised and Stroop ColorWord Test (see Fig. 3).

In the unemployed group, we found that only occupational functioning and cognitive functioning were related to scores on the Symbol Digit Modalities Test. No associations were found between FAST total scores or specific domains and the neurocognitive measures (see Fig. 4).

\section{Discussion}

This preliminary study examined the associations between clinical symptoms, social function and neurocognitive function among 81 euthymic BD patients stratified 


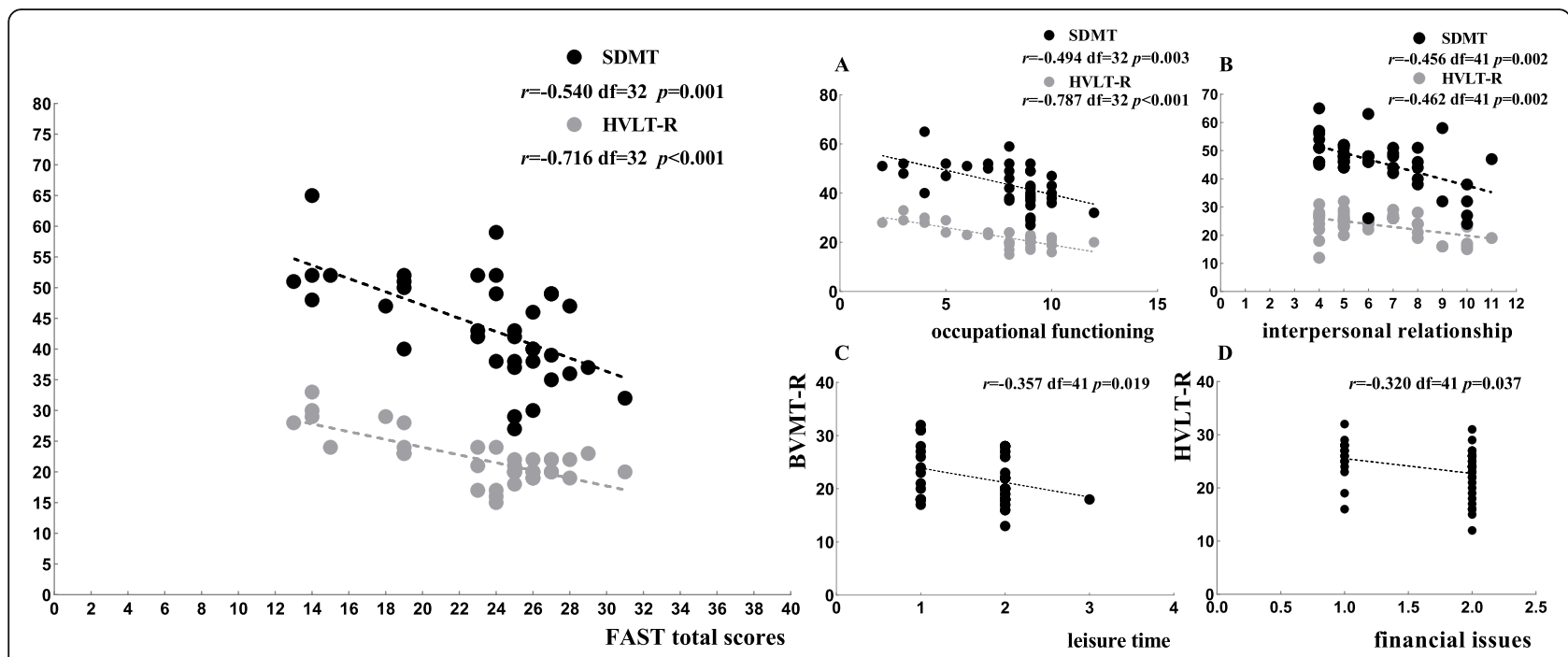

Fig. 1 The Pearson partial correlation analysis of social function and neurocognitive measures among BD-I patients. Abbreviations: SDMT (Symbol Digit Modalities Test); HVLT-R (Hopkins Verbal Learning Tests-Revised); and BVMT-R (Brief Visuospatial Memory Test-Revised)

by occupational status (employed/unemployed) and subgroups of DSM-IV BD (BD-I and BD-II). In line with earlier findings [34, 35], our findings showed that employed BD patients displayed greater social functioning (autonomy, occupational functioning, and interpersonal relationships) and performed better in verbal learning and processing speed than unemployed patients, indicating that employed BD patients could develop stronger social functions and some neurocognitive functions. In a previous cluster analysis study with euthymic BD patients, the group with lower functioning, measured by FAST scores, showed the highest unemployment rate, which indicated the main areas of functional loss in autonomy, occupational functioning, cognition and interpersonal relationships [36]. This is basically consistent with our findings. Some studies reported that employed BD patients showed greater neurocognitive functioning measured by the Assessment of Neuropsychological Status (RBANS), especially in the verbal memory domain [37]. Another study clearly showed that BD patients who have jobs may show better executive function than those without jobs [18], which is consistent with our results.

Further correlation analysis under stratification showed that social function outcomes had close ties with
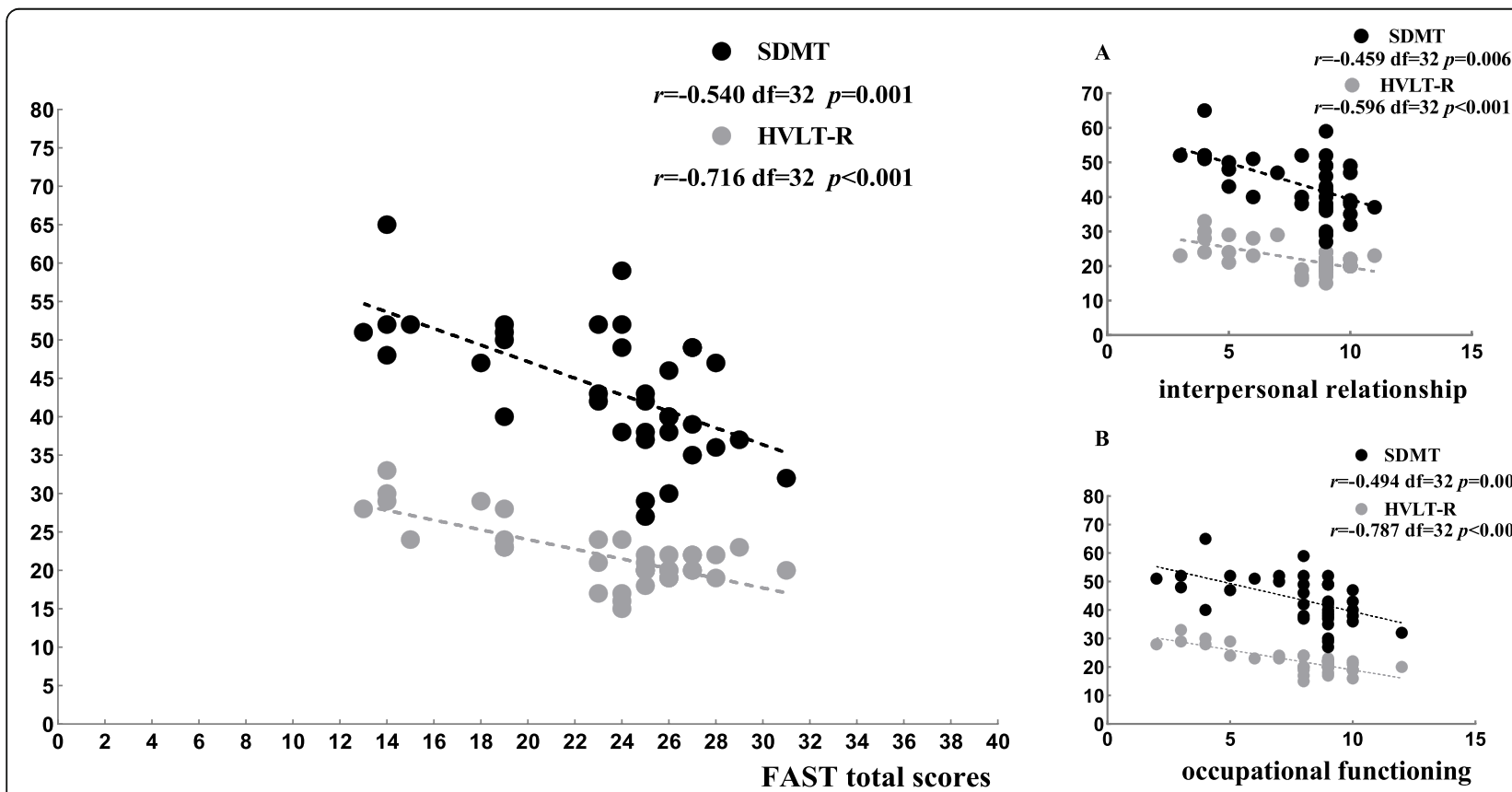

interpersonal relationship

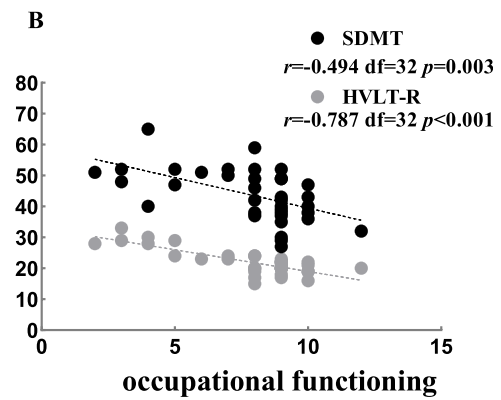

Fig. 2 The Pearson partial correlation analysis of social function and neurocognitive measures among BD-II patients. Abbreviations: SDMT (Symbol Digit Modalities Test); HVLT-R (Hopkins Verbal Learning Tests-Revised) 


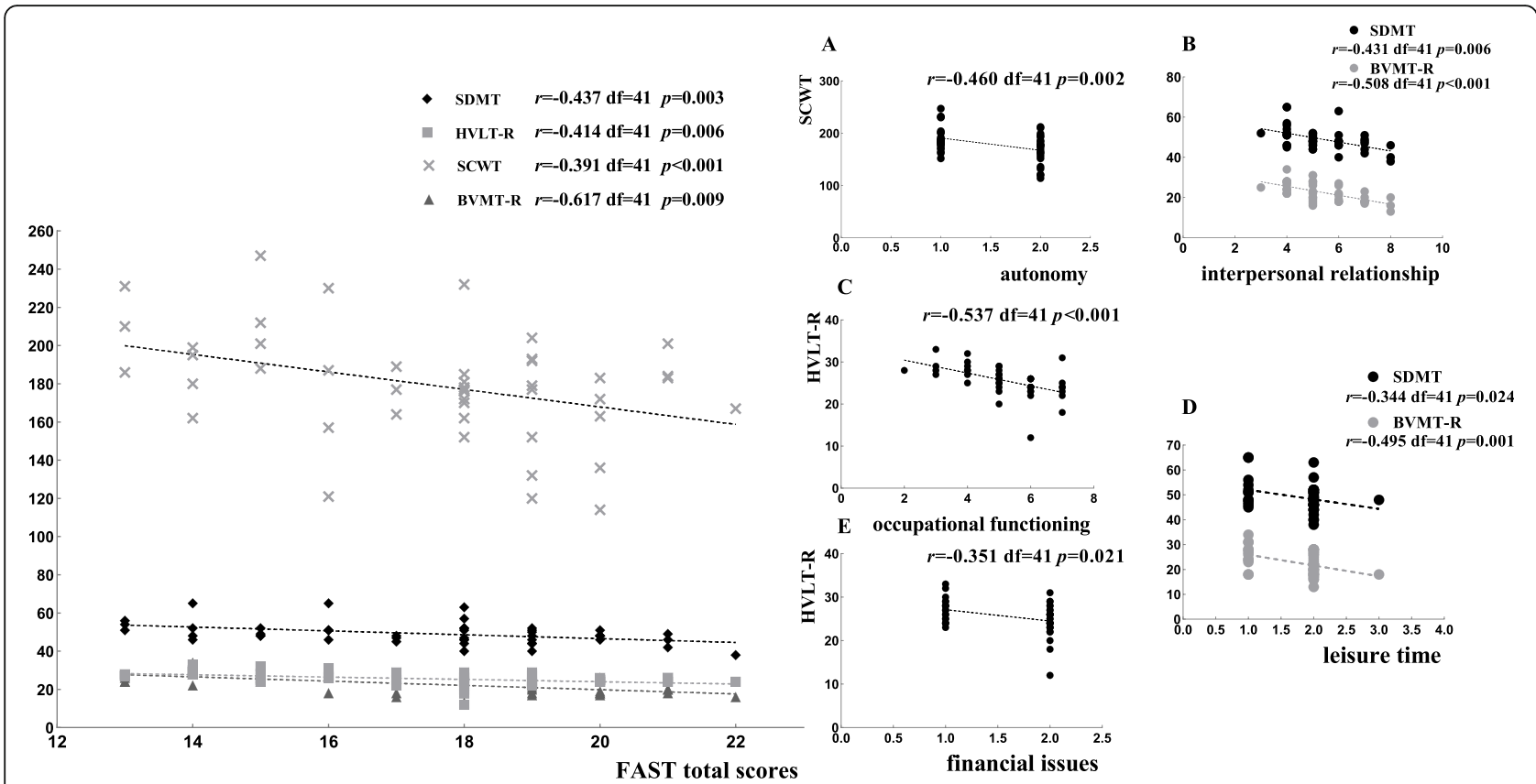

Fig. 3 The Pearson partial correlation analysis of social function and neurocognitive measures among employed BD patients. Abbreviations: SDMT (Symbol Digit Modalities Test); HVLT-R (Hopkins Verbal Learning Tests-Revised); BVMT-R (Brief Visuospatial Memory Test-Revised); and SCWT (Stroop Color-Word Test)

neurocognitive function among employed BD patients. There was a stronger correlation between neurocognitive function and the occupational and interpersonal relationship domains in the FAST, followed by the financial issues and autonomy domains. Verbal learning measures were predominantly associated with the occupational domain of the FAST in the employed group. Previous studies have demonstrated a strong correlation between verbal learning ability and occupational status [37], and our results confirmed this association. In addition, processing speed was also significantly correlated with the leisure time and interpersonal relationship domains in employed BD patients. we considered that employed person is more likely to participate in social activity, to facilitate self-management, and to promote learning and information-processing capacity. Many papers [16, 3843] have reported that social functional impairment could be associated with neurocognitive measures. Remarkably the measures of processing speed, visual memory and verbal learning were powerful determinants of functional impairment in these studies, consistent with our findings for the employed group. Bearden et al. also evidenced that baseline cognitive impairment across multiple domains, particularly working memory and speed of
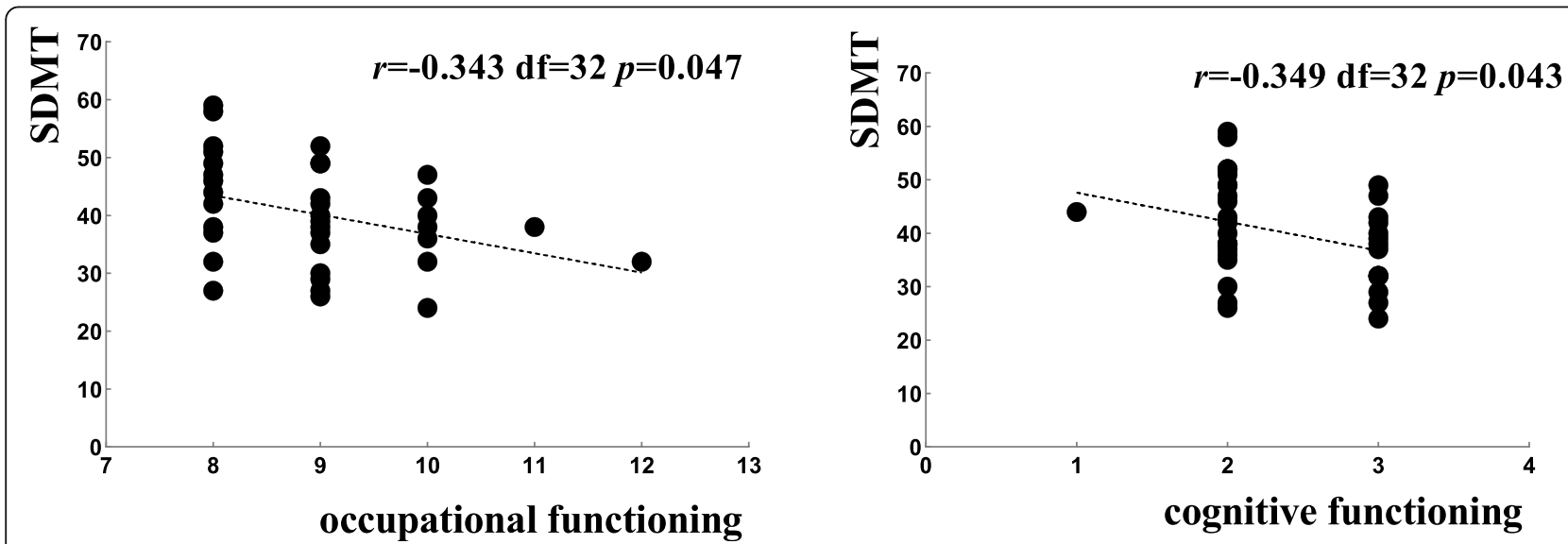

Fig. 4 The Pearson correlation analysis of social function and neurocognitive measures among unemployed BD patients. Abbreviations: SDMT (Symbol Digit Modalities Test) 
processing, were significantly associated with concurrent occupational function impairment [19] (Bearden et al., 2011). Jaeger et al. found that baseline attention and speed of processing domains could predict functional outcomes (including occupational function) over a 12-month period [44]. Most jobs require relatively strong abilities in the areas of learning, memory and processing speed. Thus, the improvement of these functions may benefit occupational performance. Unfortunately, we found that the correlation between neurocognitive function and social function significantly weakened in the unemployed group compared with the employed group (see Figs. 3 and 4), demonstrating the poorer association between social function and neurocognition in unemployed BD patients. We presume that occupational status may be a core factor in promoting overall functional development in euthymic bipolar patients.

Our findings also testified the neurocognitive differences between the BD subtypes. There were no differences in neurocognitive measures between the BD subtypes, which is in line with earlier findings [17]. Dittmann and his colleagues evaluated psychomotor speed, working memory, verbal learning, visual / constructional abilities and executive functions in euthymic bipolar patients by using the Repeatable Battery for the Assessment of Neuropsychological Status (RBANS) [45] and the Trail Making Test (TMT) A and B $[30,46]$. They also concluded that patients with both BD subtypes had similar levels of neurocognitive deficits. Similarly, another meta-analysis reported that neurocognitive differences between clinical BD subtypes were very subtle and not significant [16]. However, some studies have obtained different conclusions; for example, one study indicated that BD I patients performed worse than BD II patients in all areas of cognitive function except for working memory [47]. Another meta-analysis revealed that BD-II patients may present deficits in working memory and executive function, and more than half of the studies showed worse verbal memory. This moderate difference between BD subtypes may be complicated due to residual symptoms, number of episodes, age at illness onset, etc. [48].

Furthermore, significant differences in FAST scores and its six domains between the BD subtypes showed that BD-I patients had excellent total functioning, especially in occupational functioning and interpersonal relationships. Our findings are consistent with previous studies that showed that BD-I patients had better social function than BD-II patients did [13, 49, 50]. We considered that BD-I patients with manic episode were more likely to seek opportunities for social activity and interpersonal communication. In contrast, Dell'Osso and his colleagues found that bipolar patients with remitted BD and BD-I had significantly lower GAF scores than those with BD-II [12]. We speculate that the differences in social functioning may be influenced by functioning measures, duration of illness and education levels although no apparent differences in cognitive performance between BD subtypes [14, 51].

Besides, our correlation analyses did not suggest functional differences between the BD subtypes, indicating the same associations between processing speed and occupational functioning and interpersonal relationships both in the BD-I and BD-II patients [39]. We speculate that both BD-I and BD-II patients may exhibit similar functional impairments even in euthymia.

Our results did not show significant differences in demographic characteristics, clinical measures or social or neurocognitive functioning measures between genders. Some studies have reported that male patients could show poorer social and neurocognitive functional outcomes than female patients [41, 52], but Bücker et al. reported that males had better working memory and sustained attention than females [53]. Further study is needed to verify this gender difference in total functioning based on a larger sample size.

Several limitations of this study should be taken into consideration. First, cognitive functional assessments are scarce and do not reflect all dimensions of neurocognitive functioning in $\mathrm{BD}$ patients. The outcomes with no significant differences in neurocognitive measures between BD subtypes need to be tested using full-scale instruments in future research. Second, although occupational status can be viewed as an advantage of this study, current occupational status does not reflect the quality or stability of job performance, which is a particularly important area for understanding functional recovery and deserves further clarification. In addition, some studies have pointed out that the definition of occupation may influence the final assessment results [39, 54]. A prior study defined employment as including fulfilling domestic responsibilities at home or attending school [18], thus this association between total functioning and occupational status should be cautiously elucidated. Third, the possible effects of psychotropic medications on social function and neurocognitive function should be considered, and typical antipsychotics and partial mood stabilizers could hinder total functioning performance [55]. Fourth, we had no record on remission time in this study, while short remission time (at least one month) definitely weaken functioning outcomes. Finally, the sample size was not sufficient, which could reduce the statistical power when conducting comparison and correlation analysis.

\section{Conclusions}

In summary, our findings mainly revealed that employed BD patients may present better social and 
neurocognitive functions, and stronger associations between social functioning and neurocognitive functioning were found in employed BD patients than in unemployed BD patients. Moreover, euthymic BD-I patients may perform better occupational functioning and interpersonal relationships compared to those of euthymic BD-II patients. However, no differences in neurocognitive impairments were found between the $\mathrm{BD}$ subtypes. This preliminary finding indicated that occupational status may be an important determinant that contributes to functional recovery in euthymic BD patients.

\section{Abbreviations}

BD: bipolar disorder; HDRS-17: 17-item Hamilton Depression Rating Scale; YMRS: Young Mania Rating Scale; FAST: Functioning Assessment Short Test; MCCB: The MATRICS Consensus Cognitive Battery; TMT-A: Trail Making TestA; SDMT: Symbol Digit Modalities Test; HVLT-R: Hopkins Verbal Learning Tests-Revised; BVMT-R: Brief Visuospatial Memory Test-Revised; SCWT: Stroop Color-Word Test

\section{Acknowledgements}

Thanks to all participants for assessments and interviews in our research. Thanks to social workers and nurses to provide helps for our study.

\section{Authors' contributions \\ Yong Zhang: Conceptualization, Methodology, Resources. Xinyu Liu: Data curation, Formal analysis, Writing- Original draft preparation. Xiaojuan Ma: Supervision, Project administration. Wenchen Wang: Data curation, Investigation, Formal analysis. Jian Zhang: Data curation. Xia Sun: Data curation, Software. Xiangguang Luo: revision and editing for paper. All authors contributed to and have approved the final manuscript.}

\section{Funding}

This work was supported by Henan Key Laboratory of Neurorestoratology (HNSJXF-2018-011).

\section{Availability of data and materials}

The datasets used and analysed during the current study are available from the corresponding author on reasonable request.

\section{Declarations}

\section{Ethics approval and consent to participate}

We received approval from the Ethics Committee of Tianjin Anding Hospital. Written informed consent was obtained from all participants. All methods were carried out in accordance with relevant guidelines and regulations.

\section{Consent for publication}

Not applicable

\section{Competing interests}

The authors of this paper report no conflicts of interest in connection with this manuscript.

\footnotetext{
Author details

${ }^{1}$ Henan Key Laboratory of Neurorestoratology, the first Affiliated Hospital of Xinxiang Medical University, Xinxiang, China. ${ }^{2}$ Unit of Bipolar Disorder, Tianjin Anding Hospital, 13 Liulin Road, Hexi District, Tianjin 300222, China. ${ }^{3}$ Tianjin Medical College, Tianjin, China. ${ }^{4}$ Department of Psychiatry, Yale University School of Medicine, New Haven, CT, USA.

Received: 28 January 2021 Accepted: 26 April 2021

Published online: 07 May 2021

\section{References}

1. Grande I, Berk M, Birmaher B, Vieta E.(2016); Bipolar disorder. Lancet. 6736(15): 1-12. https://doi.org/10.1016/S0140-6736(15)00241-X.
}

2. Merikangas Kathleen R., Jin Robert., He Jian-Ping., Kessler Ronald C., Lee Sing., Sampson Nancy A., Viana Maria Carmen., Andrade Laura Helena., Hu Chiyi., Karam Elie G., Ladea Maria., Medina-Mora Maria Elena., Ono Yutaka., Posada-Villa Jose., Sagar Rajesh., Wells J Elisabeth., Zarkov Zahari., (2011). Prevalence and correlates of bipolar spectrum disorder in the world mental health survey initiative. Arch Gen Psychiatry, 68(3), 241-251. https://doi. org/10.1001/archgenpsychiatry.2011.12.

3. Huang $Y$, Wang Y, Wang H, Liu Z, Yu X, Yan J, et al. Prevalence of mental disorders in China: a cross-sectional epidemiological study. Lancet Psychiatry. 2019;6(3):211-24. https://doi.org/10.1016/S2215-0366(18)30511-X.

4. Vos T, Collaborators GB of DS (2013). Global, regional, and national incidence, prevalence, and years lived with disability for 301 acute and chronic diseases and injuries in 188 countries, 1990-2013: a systematic analysis for the Global Burden of Disease Study 2013. Lancet. 2013;6736(15): 1990-2013. https://doi.org/10.1016/S0140-6736(15)60692-4.

5. Levy B, Manove E. Functional outcome in bipolar disorder: the big picture. Depression research and treatment. 2012;2012(949248). https://doi.org/10.11 55/2012/949248.

6. Henry C, Etain B, Godin, et al. Bipolar patients referred to specialized services of care: not resistant but impaired by sub-syndromal symptoms. Results from the FACEBD cohort. Aust. N.Z. J. Psychiatry. 2015;49(10):898905. https://doi.org/10.1177/0004867415585582.

7. Martinez-Aran A, Vieta E, Torrent C, Sanchez-Moreno J, Goikolea JM, Salamero $M$, et al. Functional outcome in bipolar disorder: the role of clinical and cognitive factors. Bipolar Disord. 2007;9(1-2):103-13. https://doi. org/. https://doi.org/10.1111/j.1399-5618.2007.00327.x.

8. Suppes, T, Leverich, GS, Keck, PE, Nolen, WA, Denicoff, KD, Altshuler, LL, McElroy, SL, Rush, AJ, Kupka, R, Frye, MA, Bickel, M, Post, RM., (2001). The Stanley Foundation bipolar treatment outcome network. II. Demographics and illness characteristics of the first 261 patients. J Affect Disord, 67, 45-59. https://doi.org/10.1016/s0165-0327(01)00432-3, 1-3.

9. Tohen, M., Hennen, J., Zarate Jr, C.M., Baldessarini, R.J., Strakowski, S.M., Stoll, A.L.,Faedda, G.L., Suppes, T., Gebre-Medhin, P., Cohen, B.M., (2000). Two-year syndromal and functional recovery in 219 cases of first-episode major affective disorder with psychotic features. Am J Psychiatry 157, 220-228. https://doi.org/10.1176/appi.ajp.157.2.220, 2.

10. Hacimusalar Y., Doğan E.S., (2019). Assessment of the functioning levels and related factors in patients with bipolar disorder during remission. Noro Psikiyatr Ars, 56(3), 213-218. https://doi.org/10.29399/npa.23539.

11. Ruggero, CJ, Chelminski, I, Young, D, Zimmerman, M ., (2007). Psychosocial impairment associated with bipolar II disorder. J Affect Disord,104, 53-60. https://doi.org/10.1016/j.jad.2007.01.035, 1-3.

12. Dell'Osso, B, Dobrea, C, Cremaschi, L, Buoli, M, Miller, S, Ketter, TA, Altamura, AC., (2017). Italian bipolar II vs I patients have better individual functioning, in spite of overall similar illness severity. CNS Spectr, 22(4), 325-332. https:// doi.org/10.1017/S1092852915000887.

13. Vinberg Maj, Mikkelsen Rie Lambaek, Kirkegaard Thomas, Christensen Ellen Margrethe, Kessing Lars Vedel, (2017). Differences in clinical presentation between bipolar I and II disorders in the early stages of bipolar disorder: A naturalistic study. J Affect Disord, 208(undefined), 521-527. https://doi.org/1 0.1016/j.jad.2016.10.031.

14. Baune, B. T., Malhi, G. S., (2015). A review on the impact of cognitive dysfunction on social, occupational, and general functional outcomes in bipolar disorder. Bipolar Disord, 17 Suppl 2, 41-55. https://doi.org/10.1111/ bdi.12341.

15. Tsitsipa Eirini., Fountoulakis Konstantinos N., (2015). The neurocognitive functioning in bipolar disorder: a systematic review of data. Ann General Psychiatry, 14, 42. https://doi.org/10.1186/s12991-015-0081-z, 1.

16. Bora, E., (2018). Neurocognitive features in clinical subgroups of bipolar disorder: a meta-analysis. J Affect Disord, 229, 125-134. https://doi.org/10.1 016/j.jad.2017.12.057

17. Dittmann, S. , Hennig-Fast, K. , Gerber, S., Seemüller, F. , Riedel, M., Emanuel Severus, W., Langosch, J., Engel, RR. , Möller, HJ. , Grunze, HC., (2008). Cognitive functioning in euthymic bipolar I and bipolar II patients. . Bipolar Disord. 10, 8, 877, 887. https://doi.org/10.1111/j.1399-5618.2008.00640.x.

18. Altshuler, L., Tekell, J., Biswas, K., Kilbourne, A. M., Evans, D., Tang, D., Bauer, M. S.,(2007). Executive function and employment status among veterans with bipolar disorder. Psychiatr Serv, 58(11), 1441-1447. https://doi.org/10.11 76/ps.2007.58.11.1441.

19. Bearden, CE., Shih, VH., Green, MF., Gitlin, M., Sokolski, KN., Levander, E., Marusak, S., Hammen, C., Sugar, CA., Altshuler, LL., (2011). The impact of 
neurocognitive impairment on occupational recovery of clinically stable patients with bipolar disorder: a prospective study. Bipolar Disord, 13(4) 323-333. https://doi.org/10.1111/j.1399-5618.2011.00928.x.

20. Bonnin, C. D. M., Reinares, M., Martinez-Aran, A., Jimenez, E., SanchezMoreno, J., Sole, B., Montejo, L., Vieta, E., (2019). Improving functioning, quality of life, and well-being in patients with bipolar disorder. Int J Neuropsychopharmacol, 22(8), 467-477. https://doi.org/10.1093/ijnp/ pyz018.

21. Morosini PL, Magliano L, Brambilla L, Ugolini S, Pioli R. Development, reliability and acceptability of a new version of the DSM-IV social and occupational functioning assessment scale (SOFAS) to assess routine social functioning. Acta Psychiatr Scand. 2000;101(4):323-9. 10782554. https://doi org/10.1111/j.1600-0447.2000.tb10933.x.

22. Zhang $Y$, Long $X, M a X$, He Q, Luo X, Bian $Y$, et al. Psychometric properties of the Chinese version of the functioning assessment short test (FAST) in bipolar disorder. J Affect Disord. 2018;238:156-60. https://doi.org/10.1016/j.ja d.2018.05.019.

23. Liang SX, Yu W, Ma XJ, Zhang Y. Psychometric properties of the MATRICS Consensus Cognitive Battery (MCCB) in Chinese patients with major depressive disorder. J Affect Disord 2020; 265:132-138 https://doi.org/10.101 6/j.jad.2020.01.052.

24. APA. Diagnostic and statistical manual of mental disorders. 4th ed. Washington: American Psychiatric Association; 1994.

25. Ryan KA, Vederman AC, Kamali M, Marshall D, Weldon AL, Mclnnis MG Langenecker SA (2013). Emotion perception and executive functioning predict work status in euthymic bipolar disorder. Psychiatry Res;210(2):472478. https://doi.org/10.1016/j.psychres.2013.06.031.

26. Xie GR, Shen QJ. Use of the Chinese version of the Hamilton rating scale for depression in general population and patients with major depression. Chin J Nerv Mental Dis. 1984;10:346.

27. Young RC, Biggs JT, Ziegler VE, Meyer DA. A rating scale for mania: reliability, validity and sensitivity. Br J Psychiatry. 1978;133(5):429-35. https:// doi.org/. https://doi.org/10.1192/bjp.133.5.429.

28. Rosa, AR., Sánchez-Moreno, J., Martínez-Aran, A., Salamero, M., Torrent, C Reinares, M., Comes, M., Colom, F., Van Riel, W., Ayuso-Mateos, JL., Kapczinski, F., Vieta, E., (2007). Validity and reliability of the functioning assessment short test (FAST) in bipolar disorder. Clin Pract Epidemiol Ment Health, 3, 5. https://doi.org/10.1186/1745-0179-3-5, 1.

29. Shi C, Kang L, Yao S, Ma Y, Li T, Liang Y, et al. The MATRICS consensus cognitive battery (MCCB): co-norming and standardization in China. Schizophr Res. 2015;169(1-3):109-15. https://doi.org/10.1016/j.schres.2015.09.003.

30. Lezak MD, Howeison DB, Loring DW. Neuropsychological assessment. 4th ed. New York: Oxford University Press; 2004.

31. Smith A. Symbol digit modalities test. Los Angeles: Western Psychological Services; 1982

32. Nuechterlein, KH., Green, MF., Kern, RS., Baade, LE., Barch, DM., Cohen, JD., Essock, S., Fenton, WS., Frese, FJ., Gold, JM., Goldberg, T., Heaton, RK., Keefe, RS., Kraemer, H., Mesholam-Gately, R., Seidman, LJ., Stover, E., Weinberger, DR., Young, AS., Zalcman, S., Marder, SR., (2008). The MATR ICS consensus cognitive battery, part 1: test selection, reliability, and validity. Am J Psychiatry,165(2), 203-213. https://doi.org/10.1176/appi.a jp.2007.07010042.

33. Golden CJ. Stroop color and word test: a manual for clinical and experimental uses. Chicago: Skoelting; 1978.

34. DelBello, MP, Hanseman, D, Adler, CM, Fleck, DE, Strakowski, SM.(2007). Twelve-month outcome of adolescents with bipolar disorder following first hospitalization for a manic or mixed episode. Am J Psychiatry. 164, 4, 582, 590. https://doi.org/10.1176/ajp.2007.164.4.582, .

35. Wingo, AP., Baldessarini, RJ., Holtzheimer, PE., Harvey, PD., (2010). Factors associated with functional recovery in bipolar disorder patients. Bipolar Disord, 12, 3, 319, 326. https://doi.org/10.1111/j.1399-5618.2010.00808.x

36. Solé B., Bonnin C M., Jiménez E., Torrent C., Torres I., Varo C., Valls E. Montejo L., Gómez-Ocaña C., Tomioka Y., Vieta E., Martinez-Aran A., Reinares M.(2018). Heterogeneity of functional outcomes in patients with bipolar disorder: a cluster-analytic approach. Acta Psychiatr Scand, 137(6), 516-527. https://doi.org/10.1111/acps.12871.

37. Dickerson FB., Boronow JJ., Stallings CR., Origoni A E., Cole S., Yolken RH., (2004). Association between cognitive functioning and employment status of persons with bipolar disorder. Psychiatr Serv, 55(1), 54-58. https://doi. org/10.1176/appi.ps.55.1.54
38. Andreou C, Bozikas VP. The predictive significance of neurocognitive factors for functional outcome in bipolar disorder. Curr Opin Psychiatry. 2013;26(1): 54-9. https://doi.org/10.1097/YCO.0b013e32835a2acf.

39. Bonnin, C. D. M, Gonzalez-Pinto, A, Sole, B, Reinares, M, Gonzalez-Ortega, I, Alberich, S, Crespo, J. M, Salamero, M, Vieta, E, Martinez-Aran, A, Torrent, C, Group, Cibersam Functional Remediation., (2014). Verbal memory as a mediator in the relationship between subthreshold depressive symptoms and functional outcome in bipolar disorder. J Affect Disord, 160, 50-54. https://doi.org/10.1016/j.jad.2014.02.034

40. Duarte, W., Becerra, R., Cruise, K., (2016). The relationship between neurocognitive functioning and occupational functioning in bipolar disorder: a literature review. Eur J Psychol, 12(4), 659-678. https://doi.org/10. 5964/ejop.v12i4.909.

41. Konstantakopoulos, G., loannidi, N., Typaldou, M., Sakkas, D., Oulis, P.,(2016). Clinical and cognitive factors affecting psychosocial functioning in remitted patients with bipolar disorder. Psychiatriki, 27(3), 182-191. https://doi.org/1 0.22365/jpsych.2016.273.182

42. Sanchez-Moreno, J., Bonnin, CM., González-Pinto, A., Amann, BL., Solé, B., Balanzá-Martinez, V., Arango, C., Jiménez, E., Tabarés-Seisdedos, R., GarciaPortilla, MP., Ibáñez, A., Crespo, JM., Ayuso-Mateos, JL., Martinez-Aran, A., Torrent, C., Vieta, E., (2018). Factors associated with poor functional outcome in bipolar disorder: sociodemographic, clinical, and neurocognitive variables. Acta Psychiatr Scand, 138, 2, 145, 154. https://doi.org/10.1111/acps.12894

43. Szmulewicz, AG., Valerio, MP., Lomastro, J., Smith, JM., Chiappe, V., Martino, DJ., Igoa, A., (2018). Neurocognitive functioning in first-episode bipolar disorder: relationship with functional status. J Affect Disord, 228, 97-100. https://doi.org/10.1016/j.jad.2017.12.015

44. Jaeger, J., Berns, S., Loftus, S., Gonzalez, C., Czobor, P.r(2007). Neurocognitive test performance predicts functional recovery from acute exacerbation leading to hospitalization in bipolar disorder. Bipolar Disord, 9, 93-102. https://doi.org/10.1111/j.1399-5618.2007.00427.x, 1-2.

45. Randolph C, Tierney MC, Mohr E, Chase TN. (1998). The repeatable battery for the assessment of neuropsychological status (RBANS): preliminary clinical validity. J Clin Exp Neuropsychol; 20: 310-319. https://doi.org/10.1076/jcen.2 0.3.310.823, 3

46. Lu L, Bigler ED. Performance on original and a Chinese version of trail making test part B: a normative bilingual sample. Appl Neuropsychol. 2000; 7(4):243-6. https://doi.org/10.1207/S15324826AN0704_6.

47. Schenkel Lindsay S., West Amy E., Jacobs Rachel., Sweeney John A., Pavuluri Mani N. (2012). Cognitive dysfunction is worse among pediatric patients with bipolar disorder type I than type II. J Child Psychol Psychiatry, 53(7), 775-781. https://doi.org/10.1111/j.1469-7610.2011.02519.x.

48. Solé B., Martínez-Arán A., Torrent C., Bonnin C M., Reinares M., Popovic D., Sánchez-Moreno J., Vieta E., (2011). Are bipolar II patients cognitively impaired? A systematic review. Psychol Med, 41(9), 1791-1803. https://doi. org/10.1017/S0033291711000018

49. Kupka, Ralph W. , Altshuler, Lori L., Nolen, Willem A., Suppes, Trisha, Luckenbaugh, David A. , Leverich, Gabriele S., Frye, Mark A., Keck Jr., Paul E. , McElroy, Susan L. , Grunze, Heinz, Post, Robert M. , (2007). Three times more days depressed than manic or hypomanic in both bipolar I and bipolar II disorder. Bipolar Disord, 9(5), 531-535. https://doi.org/10.1111/j.13 99-5618.2007.00467.x.

50. Vieta, E. (2010). Long-term treatment of bipolar depression and other issues. J Clin Psychiatry, 71, 03, e07. https://doi.org/10.4088/JCP.8125tx4C

51. Chen Maxine., Fitzgerald Heather M., Madera Jessica J., Tohen Mauricio., (2019). Functional outcome assessment in bipolar disorder: a systematic literature review. Bipolar Disord, 21(3), 194-214. https://doi.org/10.1111/ bdi.12775.

52. Vaskinn, A., Sundet, K., Simonsen, C., Hellvin, T., Melle, I., Andreassen, OA ,(2011). Sex differences in neuropsychological performance and social functioning in schizophrenia and bipolar disorder. Neuropsychology, 25(4), 499-510. https://doi.org/10.1037/a0022677.

53. Bücker, J, Popuri, S, Muralidharan, K, Kozicky, JM, Baitz, HA, Honer, WG, Torres, IJ, Yatham, LN., (2014). Sex differences in cognitive functioning in patients with bipolar disorder who recently recovered from a first episode of mania: data from the systematic treatment optimization program for early mania (STOP-EM). J Affect Disord, 155, 162-168. https://doi.org/10.101 6/j.jad.2013.10.044

54. Kozma, C., Dirani, R., Canuso, C., \& Mao, L.,(2010). Change in employment status over 52 weeks in patients with schizophrenia: an observational study. 
Current medical research and opinion., Curr Med Res Opin, 27(2), 327-333. https://doi.org/10.1185/03007995.2010.541431.

55. Dias, W., Balanzá-Martinez, V., Soeiro-de-Souza, MG., Moreno, RA., Figueira, ML, Machado-Vieira, R., Vieta, E., (2012). Pharmacological approaches in bipolar disorders and the impact on cognition: a critical overview. Acta Psychiatr Scand, 126(5), 315-331. https://doi.org/10.1111/j.1600-0447.2012.01910.x.

\section{Publisher's Note}

Springer Nature remains neutral with regard to jurisdictional claims in published maps and institutional affiliations.

Ready to submit your research? Choose BMC and benefit from:

- fast, convenient online submission

- thorough peer review by experienced researchers in your field

- rapid publication on acceptance

- support for research data, including large and complex data types

- gold Open Access which fosters wider collaboration and increased citations

- maximum visibility for your research: over $100 \mathrm{M}$ website views per year

At $B M C$, research is always in progress.

Learn more biomedcentral.com/submissions 